Central European Journal of Energetic Materials, 2016, 13(2), 469-482

\title{
The Effect of Different Copper Salts on the Mechanical and Ballistic Characteristics of Double Base Rocket Propellants
}

\author{
Nour ABDEL-GHANI ${ }^{1}$, Ahmed ELBEIH ${ }^{2 *}$, Farag HELAL $^{3}$
}

${ }^{1}$ Department of Chemistry, Faculty of Science, Cairo University, Giza, Egypt

${ }^{2}$ Military Technical College, Kobry Elkobbah, Cairo, Egypt

${ }^{3}$ Center of Excellence in Scientific and Technological, Ministry of Military Production, El-Salam, Egypt

*E-mail: elbeih.czech@gmail.com

\begin{abstract}
This paper discusses the enhancement in the ballistic performance of double base rocket propellants (DBRPs) by the addition of different copper salts $v s$ lead salts as burning rate modifiers through stable combustion and the formation of a plateau region in the low pressure region. Compositions based on DBRPs containing different percentages of lead stearate and different types of copper salts were prepared and studied. For comparison, a conventional DBRP was studied. The ignition temperature and heat of combustion were determined experimentally, and the mechanical properties were measured and evaluated. The performance in terms of ballistic characteristics (burning rate, operating pressure) were measured at different throat diameters $(8,8.5,9,9.5 \mathrm{~mm})$ and at different temperatures $\left(-20\right.$ and $\left.50^{\circ} \mathrm{C}\right)$. Specific impulses were calculated using the ICT thermodynamic code. The experimental data from the proportional study indicate that the compositions containing the studied burning rate modifiers are superior to the original DBRP in respect of ballistic performance and mechanical properties.
\end{abstract}

Keywords: double base rocket propellant, burning rate modifiers, ballistic performance, mechanical properties 


\section{Introduction}

Double base rocket propellants (DBRPs) consist mainly of nitroglycerine (NG) and nitrocellulose (NC) $[1,2]$. The burning rate of DBRPs varies greatly with pressure, so that during their combustion in a rocket motor, small fluctuations in the combustion are translated into significant pressure variations [3]. Ballistic additives are added to the propellant to reduce the sensitivity of the burning process to pressure fluctuations, as well as to catalyze the burning rates to the higher regimes. Some of these additives permit a burning rate independent of the pressure, within a given range of pressures (the plateau effect). When the burning rate decreases with increasing pressure, this phenomenon is called the mesa effect $[4,5]$.

The effect of lead oxide $(\mathrm{PbO})$ with lead copper salts of organic acids was studied. Basic lead and copper salts of aliphatic acids have been found to produce more or less similar catalytic and plateau effects, whereas basic copper salts of aromatic acids were comparatively more effective in producing higher burning rates than the basic lead salts, although the reduction of the pressure index (exponent) values was more pronounced with the basic lead salts [6]. These results have been explained in the light of existing theories on catalysis and platonization. To understand the role of lead salts of organic acids in the combustion of double base rocket propellants, the thermal decomposition behaviour of propellants was studied by DTA and TGA methods. Catalyzed propellants (including different lead salts) decomposed at lower temperatures than the control propellant sample, which was composed of NC, NG, carbamite, dinitrotoluene and dibutyl phthalate, without a ballistic modifier [7, 8].

The effect of adding a combination of a lead component, a tin component and a copper component as ballistic modifiers for DBRPs was studied in a US patent [9]. The effect of $\mathrm{PbO}_{2}, \mathrm{SnO}_{2}, \mathrm{TiO}_{2}$, and $\mathrm{Bi}$ on the combustion of propellants of various compositions was investigated. It was established that $\mathrm{SnO}_{2}, \mathrm{TiO}_{2}$ and $\mathrm{Bi}$ have a significant effect on the burning rate of propellants without carbon black and additional plasticizers [10]. The calculated thermodynamic parameters, from the TGA-DTA curves, gave real information about the effect of the different burning rate modifiers on the thermal decomposition, the rate of decomposition, the reaction mechanism and the improvement that might occur in the ballistic performance characteristics of the propellants $[11,12]$. The primary process in the combustion of DBRPs is the decomposition of the organic nitrates, $\mathrm{RO}-\mathrm{NO}_{2}$. The cleavage of the $\mathrm{O}-\mathrm{N}$ bond gives a free radical and $\mathrm{NO}_{2}$. This primary reaction is followed by subsequent reactions between the $\mathrm{NO}_{2}$ and other decomposition products. It ultimately leads to the final products, namely $\mathrm{CO}_{2}, \mathrm{H}_{2}, \mathrm{H}_{2} \mathrm{O}, \mathrm{N}_{2}$. . etc. 
During the steady state of combustion, four reaction zones, namely foam or subsurface reaction, fizz, dark and luminous zones have been identified [13].

The present work is divided into two parts. The first part includes a study of the influence of the different burning rate modifiers (mixtures of lead stearate and different copper [organic (aliphatic and aromatic) and inorganic] salts) on the ignition temperature, the heat of combustion and the mechanical properties of the prepared formulations at different temperatures. The second part involves a study of the influence of the suggested burning rate modifiers on the ballistic performance characteristics, such as burning rate, operating pressure and specific impulse of the DBRPs at two different temperatures $\left(+50\right.$ and $\left.-20{ }^{\circ} \mathrm{C}\right)$ using different throat diameters $(8,8.5,9,9.5 \mathrm{~mm})$.

\section{Experimental}

\subsection{Materials and preparation of DBRP formulations}

Nitrocellulose (NC) with $12 \%$ nitrogen content, nitroglycerin $(\mathrm{NG})$ and dinitrotoluene (DNT) were produced by the Abu Zaabal company. Centralite I (C-I, diethyl diphenylurea), lead stearate, copper oxide, copper acetate, copper salicylate (Sigma-Aldrich), dibutyl phathalate (DBP) (Fluka), and carbon black (Riedel-Dehaën) were used in the preparation of the investigated double base rocket propellant samples.

Seven different DBRP compositions based on NG and NC with different percentages of lead stearate and copper (salicylate, acetate and oxide) salts were formulated. Each sample contains 57.7, 30.0, 5.0, 2.0, 3.0 and $0.3 \%$, of NC, NG, 2,4-dinitrotoluene (DNT), centralite I, dibutyl phathalate (DBP) and carbon black, respectively. The different compositions of the burning rate modifiers studied in these propellants are listed in Table 1. All of the samples were made on the pilot scale (10 kg batch) by using the extrusion method [14]. The control propellant sample and other samples (S1-S6) were extruded into multi-tubular configurations.

Table 1. Composition percentages of various burning rate modifiers in the control and the studied propellants

\begin{tabular}{|l|c|c|c|c|c|c|c|}
\hline Sample No. & Control & S1 & S2 & S3 & S4 & S5 & S6 \\
\hline Lemponents & 2.0 & 1.7 & 1.6 & 1.5 & 1.4 & 1.6 & 1.6 \\
\hline Copper salts [\%] $[\%]$ & 0.0 & $0.3^{\mathrm{a}}$ & $0.4^{\mathrm{a}}$ & $0.5^{\mathrm{a}}$ & $0.6^{\mathrm{a}}$ & $0.4^{\mathrm{b}}$ & $0.4^{\mathrm{c}}$ \\
\hline
\end{tabular}

${ }^{\mathrm{a}}$ Copper salicylate; ${ }^{\mathrm{b}}$ Copper acetate; ${ }^{\mathrm{c}}$ Copper oxide. 


\subsection{Ignition temperature measurements}

The ignition temperature of each sample was measured by a Julius Peter's [15] apparatus. Three samples from each formulation were placed in test tubes and these tubes were then placed vertically into the heating device simultaneously. The temperature was increased uniformly at a heating rate of $5{ }^{\circ} \mathrm{C} \cdot \mathrm{min}^{-1}$ until the point of autoignition of the sample was reached. The ignition temperature was recorded digitally on the control unit and the mean temperature of the three samples (the difference between two readings was not greater than $2{ }^{\circ} \mathrm{C}$ ) is reported in Table 2.

\subsection{Heat of combustion measurements}

A PARR 6200 adiabatic bomb calorimeter was used for determining the internal energy of combustion of all of the formulations studied. A weighed sample was placed in contact with a platinum wire inside the bomb and then filled with an excess of oxygen $(20 \mathrm{~atm})$. The high pressure of oxygen is necessary to ensure complete combustion. The measurements are based on recording the temperature increase in the calorimetric vessel after the combustion process. The results obtained from the measurements are reported in Table 2 as the heat of combustion.

\subsection{Mechanical testing}

A Zwick universal mechanical testing machine (model 1487) was used to determine the maximum stress $\left(\sigma_{\mathrm{m}}\right)$ and maximum strain $\left(\varepsilon_{\mathrm{m}}\right)$ of the propellant formulations. Ten specimens in multi-tubular grain form, having length $12.5 \mathrm{~mm}$ and diameter $25 \mathrm{~mm}$ were prepared. Five of these specimens were kept at $+25^{\circ} \mathrm{C}$ and the others at $+50{ }^{\circ} \mathrm{C}$ for $2 \mathrm{~h} \mathrm{[16]}$. The mean value of five measurements of each formulation was recorded as shown in Table 2.

\subsection{Ballistic performance measurements}

The system used for measuring the ballistic performance of the double base rocket propellants was a TELDYNE TABER bonded strain gauge pressure transducer (model 206). This system consists of an electrical signal which passes through the data acquisition system, amplifier, calibrator, high-level selector, digital voltmeter, UV (ultra violet) recorder and pressure transducer. The average burning rate and operating pressure were determined by this system using a standard two inch rocket motor. The samples were placed in steel cylinders then loaded in the testing motor. The measurements were made using different throat diameters $(8,8.5,9$ and $9.5 \mathrm{~mm})$ at different initial temperatures $(-20$ and $+50{ }^{\circ} \mathrm{C}$ ) [17]. The results of the experimental measurements are presented in Table 3. 


\subsection{Thermodynamic calculations}

Calculations of the thermodynamic properties of the equilibrium mixtures were performed using the ICT Thermodynamic Code [18]. The code computes chemical equilibrium by solving the non-linear equations derived from the mass action and mass balance expressions. The calculations were performed for isobaric adiabatic combustion at 7.0 $\mathrm{MPa}$, assuming an adiabatic expansion through a nozzle in one-dimensional flow at chemical equilibrium and at an expansion ratio of 70:1. The results of the calculations are presented in Table 3 .

\section{Results and Discussion}

It was observed from Table 2 that the control sample has the highest ignition temperature of all of the samples studied, and the addition of the different percentages of copper salts caused decreases in the ignition temperature.

Table 2. Results of experimental measurements

\begin{tabular}{|c|c|c|c|c|c|c|}
\hline \multirow{2}{*}{$\begin{array}{l}\text { Property } \\
\text { Sample } \\
\text { No. }\end{array}$} & \multirow{2}{*}{$\begin{array}{c}\text { Ignition } \\
\text { temperature } \\
{\left[{ }^{\circ} \mathrm{C}\right]}\end{array}$} & \multirow{2}{*}{$\begin{array}{c}\text { Heat of } \\
\text { combustion } \\
{[\mathrm{cal} / \mathrm{g}]}\end{array}$} & \multicolumn{2}{|c|}{$\begin{array}{c}\text { Max. stress } \\
\sigma_{\mathrm{m}}[\mathrm{MPa}]\end{array}$} & \multicolumn{2}{|c|}{$\begin{array}{c}\text { Max. strain } \\
\varepsilon_{\mathrm{m}}[\%]\end{array}$} \\
\hline & & & $50^{\circ} \mathrm{C}$ & $25^{\circ} \mathrm{C}$ & $50^{\circ} \mathrm{C}$ & $25^{\circ} \mathrm{C}$ \\
\hline Control & 192 & 818.98 & 599.87 & 1990.37 & 39.04 & 31.41 \\
\hline S1 & 184 & 820.14 & 735.49 & 2418.39 & 48.76 & 39.20 \\
\hline S2 & 182 & 821.58 & 797.72 & 2634.04 & 54.75 & 39.87 \\
\hline S3 & 176 & 822.34 & 802.92 & 2640.22 & 55.11 & 40.16 \\
\hline S4 & 173 & 824.25 & 827.71 & 2734.69 & 56.48 & 40.26 \\
\hline S5 & 170 & 828.20 & 796.35 & 2631.32 & 51.31 & 39.68 \\
\hline S6 & 171 & 827.45 & 753.42 & 2649.53 & 53.79 & 39.46 \\
\hline
\end{tabular}

On the other hand, the heat of combustion of the control sample has the lowest value compared with the other samples containing different percentages of the copper salts studied. These results are represented in Figure 1 which indicates a relation between the ignition temperatures and the heats of combustion for all of the samples studied.

From Figure 1, a relationship, represented by a straight line, was observed between the ignition temperatures of the samples and their heats of combustion. This relation proved that increasing the percentage of copper salicylate in the sample caused an increase in the heat of combustion and a decrease in the 
ignition temperature of the sample. This means that the control sample has the best thermal stability compared with the other samples studied.

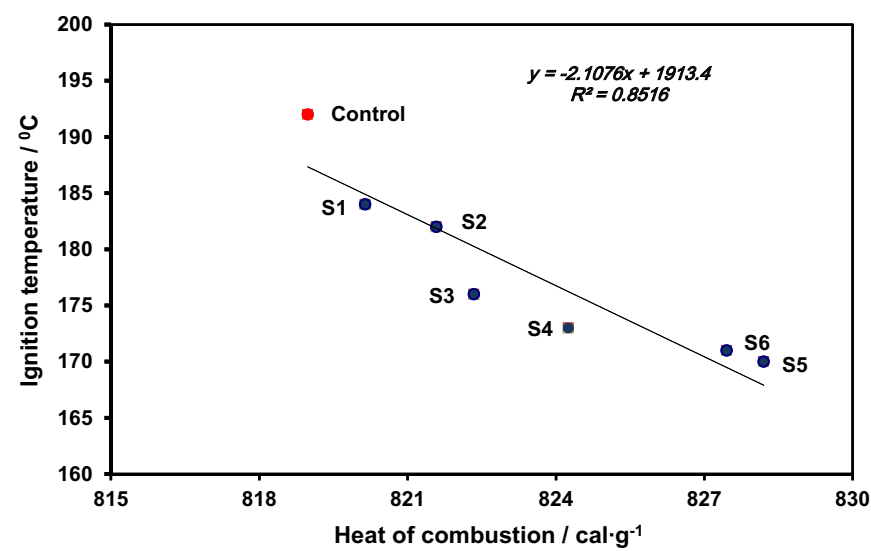

Figure 1. Relation between the ignition temperatures of the samples and their heats of combustion.

From the mechanical parameters presented in Table $2, \sigma_{\mathrm{m}}$ and $\varepsilon_{\mathrm{m}}$, of propellants S1-S6, it is observed that the use of the studied modifiers led to improvements in the mechanical properties of these propellants at different temperatures $\left(+50\right.$ and $\left.+25^{\circ} \mathrm{C}\right)$ compared with those of the control, which is very important for good functioning of rocket motors during their use and storage [19]. Figures 2 and 3 present the relations between the maximum stress and strain of all of the samples studied at +50 and $+25{ }^{\circ} \mathrm{C}$. It is clear from these figures that the control sample has the lowest stress and strain results. The addition of different copper salts caused an improvement in the mechanical properties compared with the control sample. This result might be interpreted in terms of homogeneity and good mixing of the studied propellants, which protects them from the attack by atmospheric moisture, which might cause weak points in their structure [19]. 


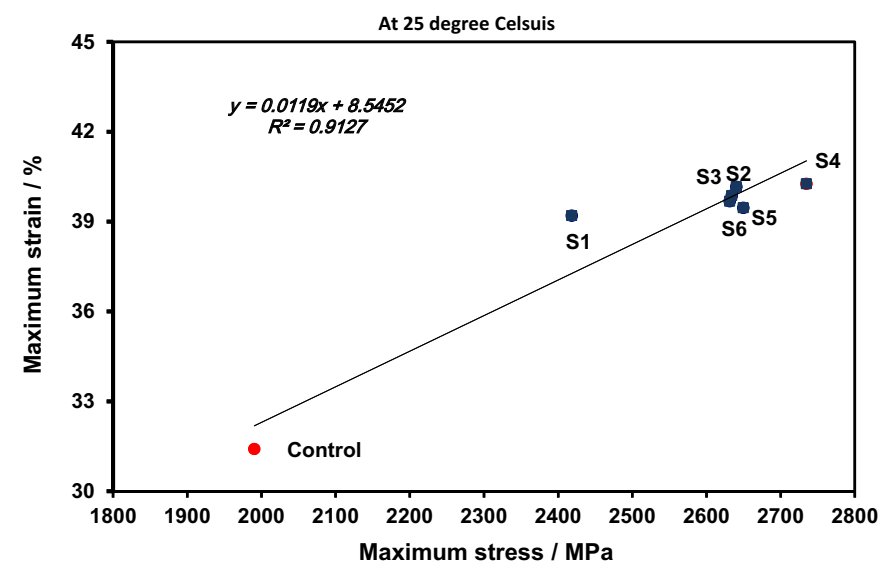

Figure 2. Relationship between the maximum stress and maximum strain of the samples at $25^{\circ} \mathrm{C}$.

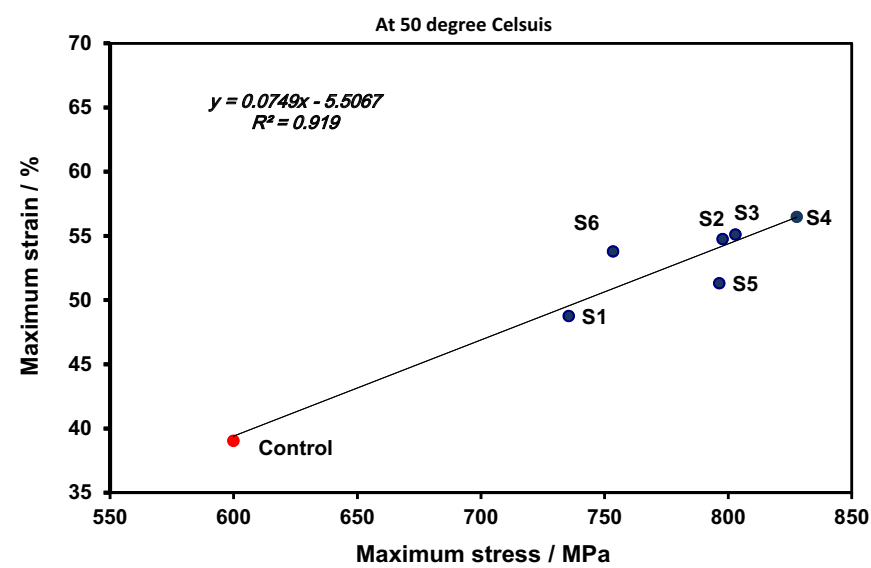

Figure 3. Relationship between the maximum stress and maximum strain of the samples at $50^{\circ} \mathrm{C}$.

Another explanation may be connected to the suitability of the particle size of the added burning rate modifiers to fill the spaces inside the matrix of the propellant samples, as supported by an X-ray test. It is also clear that increasing the temperature of the samples (to $50^{\circ} \mathrm{C}$ ) has a great effect on the ability of the samples to resist high stresses. 
Table 3. Ballistic performance characteristics of the control and the studied propellants

\begin{tabular}{|c|c|c|c|c|c|c|c|}
\hline \multirow{3}{*}{$\begin{array}{c}\text { Sample } \\
\text { No. }\end{array}$} & \multicolumn{2}{|c|}{ Theoretical calculations } & \multicolumn{5}{|c|}{ Experimental measurements } \\
\hline & \multirow{2}{*}{$\begin{array}{c}\text { Specific } \\
\text { impulse } \\
{[\mathrm{s}]}\end{array}$} & \multirow{2}{*}{\begin{tabular}{|c} 
Combustion \\
temperature \\
{$[\mathrm{K}]$}
\end{tabular}} & \multirow{2}{*}{$\begin{array}{c}\text { Throat } \\
\text { diameter } \\
{[\mathrm{mm}]}\end{array}$} & \multicolumn{2}{|c|}{ at $50{ }^{\circ} \mathrm{C}$} & \multicolumn{2}{|c|}{ at $-20^{\circ} \mathrm{C}$} \\
\hline & & & & $\begin{array}{c}\mathrm{P}_{\mathrm{c}} \\
\text { [bar] }\end{array}$ & $\begin{array}{c}\mathrm{r}_{\mathrm{b}} \\
{[\mathrm{mm} / \mathrm{s}]}\end{array}$ & $\begin{array}{c}\mathrm{P}_{\mathrm{c}} \\
\text { [bar] }\end{array}$ & $\begin{array}{c}\mathrm{r}_{\mathrm{b}} \\
{[\mathrm{mm} / \mathrm{s}]}\end{array}$ \\
\hline \multirow{4}{*}{ Control } & \multirow{4}{*}{220.5} & \multirow{4}{*}{2276} & 8 & 149.23 & 13.94 & 126.30 & 12.34 \\
\hline & & & 8.5 & 125.22 & 13.03 & 107.28 & 10.72 \\
\hline & & & 9 & 104.18 & 12.87 & 80.98 & 10.60 \\
\hline & & & 9.5 & \begin{tabular}{|l|}
84.19 \\
\end{tabular} & 11.17 & 59.06 & 8.32 \\
\hline \multirow{4}{*}{$\mathrm{S} 1$} & \multirow{4}{*}{220.7} & \multirow{4}{*}{2284} & 8 & 140.29 & 13.05 & 117.01 & 11.39 \\
\hline & & & 8.5 & 108.77 & 12.30 & 93.99 & 11.09 \\
\hline & & & 9 & 95.87 & 12.21 & 72.64 & 10.93 \\
\hline & & & 9.5 & 78.35 & 10.99 & 59.54 & 8.30 \\
\hline \multirow{4}{*}{ S2 } & \multirow{4}{*}{220.7} & \multirow{4}{*}{2286} & 8 & 148.30 & 13.70 & 118.28 & 11.39 \\
\hline & & & 8.5 & 123.28 & 12.95 & 97.77 & 10.98 \\
\hline & & & 9 & 98.48 & 12.13 & 86.62 & 10.54 \\
\hline & & & 9.5 & 79.44 & 10.94 & 70.35 & 9.58 \\
\hline \multirow{4}{*}{ S3 } & \multirow{4}{*}{220.8} & \multirow{4}{*}{2288} & 8 & 151.06 & 14.06 & 123.88 & 12.12 \\
\hline & & & 8.5 & 121.70 & 13.46 & 95.55 & 11.29 \\
\hline & & & 9 & 101.20 & 12.83 & 89.97 & 11.05 \\
\hline & & & 9.5 & 84.97 & 11.93 & 65.04 & 9.05 \\
\hline \multirow{4}{*}{ S4 } & \multirow{4}{*}{220.9} & \multirow{4}{*}{2291} & 8 & 155.94 & 14.41 & 123.44 & 12.04 \\
\hline & & & 8.5 & 120.82 & 13.58 & 105.33 & 11.98 \\
\hline & & & 9 & 112.36 & 13.45 & 86.49 & 11.91 \\
\hline & & & 9.5 & 91.05 & 12.70 & 72.21 & 9.78 \\
\hline \multirow{4}{*}{ S5 } & \multirow{4}{*}{220.9} & \multirow{4}{*}{2289} & 8 & 151.32 & 14.19 & 123.86 & 11.93 \\
\hline & & & 8.5 & 115.08 & 13.31 & 95.56 & 11.21 \\
\hline & & & 9 & 102.51 & 13.11 & 86.00 & 10.73 \\
\hline & & & 9.5 & 65.64 & 9.55 & 74.82 & 10.18 \\
\hline \multirow{4}{*}{ S6 } & \multirow{4}{*}{221.1} & \multirow{4}{*}{2299} & 8 & 168.01 & 15.44 & 142.68 & 13.31 \\
\hline & & & 8.5 & 127.91 & 14.32 & 105.10 & 12.39 \\
\hline & & & 9 & 84.82 & 12.84 & 87.94 & 12.23 \\
\hline & & & 9.5 & 72.10 & 12.71 & 64.64 & 8.90 \\
\hline
\end{tabular}

The chamber pressure-time curves obtained from the Teledyne taber system at $+50{ }^{\circ} \mathrm{C}$ showed that the control and the propellants $\mathrm{S} 1-\mathrm{S} 4$, and $\mathrm{S} 6$ form stable burning areas on the chamber $\mathrm{P} / \mathrm{t}$ curves using throat diameters of $8,8.5,9$ and $9.5 \mathrm{~mm}$. 
For sample $\mathrm{S} 5$, stable burning over the $\mathrm{P} / \mathrm{t}$ curves was obtained using throat diameters of $8,8.5$ and $9 \mathrm{~mm}$, while relatively irregular burning over this curve was obtained with a throat diameter of $9.5 \mathrm{~mm}$. The unstable combustion of this sample may be attributed to the increase in throat diameter, which in turn led to lower chamber pressure levels than those at which the stable burning was observed [20]. Figure 4 represents examples of P/t curves for sample S5.

The $\mathrm{P} / \mathrm{t}$ curves obtained for the control and propellants $\mathrm{S} 2-\mathrm{S} 4$ at $-20{ }^{\circ} \mathrm{C}$ showed stable burning over these curves at throat diameters of $8,8.5$ and $9 \mathrm{~mm}$, while relatively irregular burning was obtained for these samples at a throat diameter of $9.5 \mathrm{~mm}$. For propellants $\mathrm{S} 1$ and $\mathrm{S} 6$, stable burning over the $\mathrm{P} / \mathrm{t}$ curves was obtained by using throat diameters of $8,8.5,9$ and $9.5 \mathrm{~mm}$. For sample $\mathrm{S} 5$, stable burning over the $\mathrm{P} / \mathrm{t}$ curve was obtained at throat diameters of $8,8.5$ and $9 \mathrm{~mm}$, while relatively oscillatory burning was obtained for this sample at a throat diameter of $9.5 \mathrm{~mm}$. The relatively irregular burning obtained over the $\mathrm{P} / \mathrm{t}$ curves at a throat diameter of $9.5 \mathrm{~mm}$ for samples $\mathrm{S} 2-\mathrm{S} 4$ at $-20{ }^{\circ} \mathrm{C}$ may be attributed to two reasons. Firstly, due to the increase in the throat diameter $(9.5 \mathrm{~mm})$ which in turn led to a decrease in the chamber pressure, to lower levels than those attained under the stable burning, i.e. at throat diameters of $8,8.5$ and $9 \mathrm{~mm}$, over the $\mathrm{P} / \mathrm{t}$ curves for these samples. Secondly, due to the decrease in the initial temperature (from +50 to $-20^{\circ} \mathrm{C}$ ) which in turn might also lead to lower chamber pressures than those attained under stable burning, i.e. at throat diameters of $8,8.5$ and $9 \mathrm{~mm}$ at $+50{ }^{\circ} \mathrm{C}$, over the $\mathrm{P} / \mathrm{t}$ curves, which was obtained for these samples.

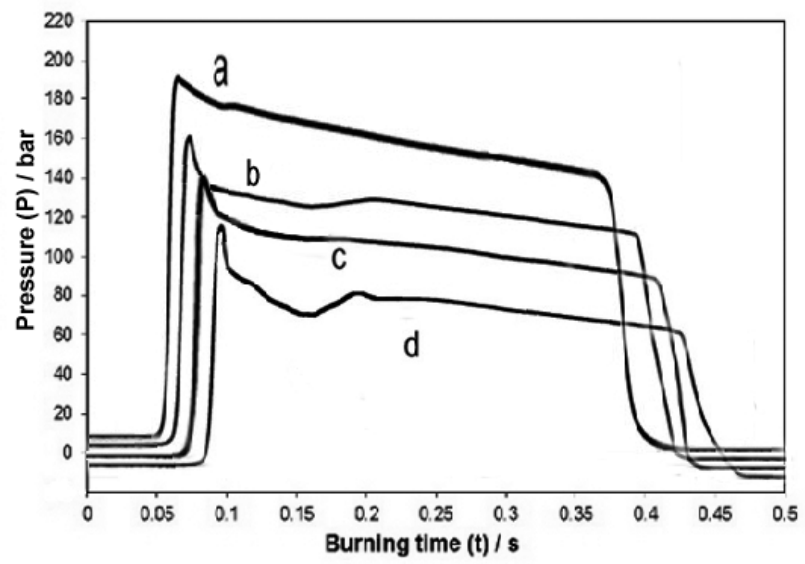

Figure 4. The $\mathrm{P} / \mathrm{t}$ curves of sample $\mathrm{S} 5$ at $+50{ }^{\circ} \mathrm{C}$ using throat diameters; a) $8 \mathrm{~mm}$, b) $8.5 \mathrm{~mm}$, c) $9 \mathrm{~mm}$, d) $9.5 \mathrm{~mm}$. 
Finally, it is clear from the previous results that at +50 and $-20{ }^{\circ} \mathrm{C}$, the chamber pressure of the propellants was increased by increasing the temperature or by decreasing the throat diameter. It was found that the ignition of the propellant samples was spontaneous and the combustion was generally stable and plateau regions could be attained using throat diameters of $8,8.5$ and $9 \mathrm{~mm}$ [21].

Figure 5 shows the logarithmic relation between the chamber pressure $\left(\mathrm{P}_{\mathrm{c}}\right)$ and the burning rate $\left(\mathrm{r}_{\mathrm{b}}\right)$ of DBRPs at $+50{ }^{\circ} \mathrm{C}$ and $-20^{\circ} \mathrm{C}$, and the experimental results from the TELEDYNE TABER SYSTEM are reported in Table 3. These results indicate that at $+50{ }^{\circ} \mathrm{C}$, the suggested modifiers in propellants $\mathrm{S} 1$ and S4-S6 improve the ballistic performance of these samples through enhancement of the burning rate at lower pressures and exhibit plateau regions (where there is no dependence of the burning rate on the pressure value) in the logarithmic relation between $P_{c}$ and $r_{b}$, where the slope (pressure exponent $(n)$ ) is zero [3, 22].
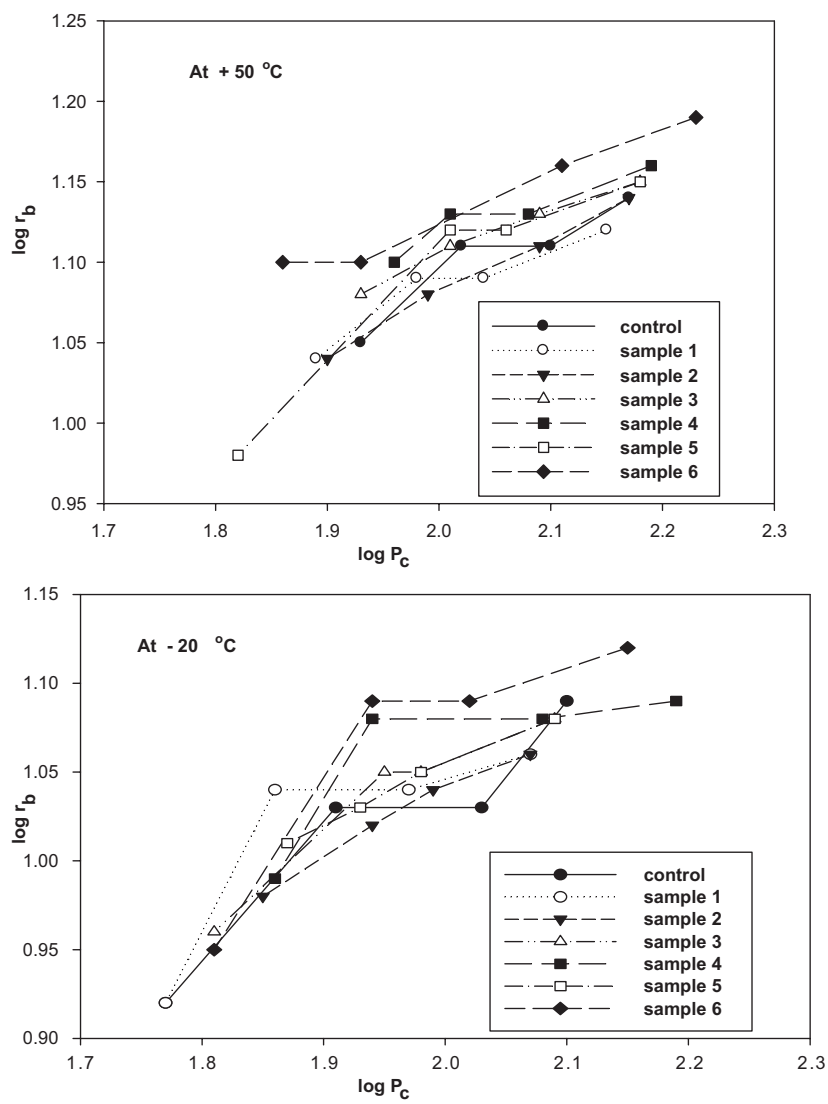

Figure 5. Relation between $\log \mathrm{P}_{\mathrm{c}}$ and $\log \mathrm{r}_{\mathrm{b}}$ of the control and the studied propellants at +50 and $-20{ }^{\circ} \mathrm{C}$. 
The results showed also that the suggested modifiers in the propellants $\mathrm{S} 2$ and $\mathrm{S} 3$, which had $\mathrm{n}=0.3$ and 0.25 respectively, led to development in the ballistic performance but with no plateau regions, and the straight lines in the logarithmic relation of these samples may be due to the dependence of the burning rate on the pressure value (Figure 5).

Furthermore, these increases in burning rate characteristics may be due to the exothermic reactions that occur between lead and copper salts and the evolved combustion gases. The heat released is due to the conversion of $\mathrm{CO}_{2}$ to $\mathrm{CO}$ and $\mathrm{H}_{2} \mathrm{O}$ to $\mathrm{H}_{2}[13,23]$.

Simultaneously, the results at $-20{ }^{\circ} \mathrm{C}$ indicate that the suggested modifiers in propellants $\mathrm{S} 1, \mathrm{~S} 3, \mathrm{~S} 4$ and $\mathrm{S} 6$ augment the ballistic performance of these propellants by increasing the burning rate in the lower pressure ranges compared with the control, and exhibit a plateau region in the logarithmic relation between $\mathrm{P}_{\mathrm{c}}$ and $\mathrm{r}_{\mathrm{b}}$ in which the slope is zero (Figure 5). The modifiers studied in propellants $\mathrm{S} 2$ and S5 led to development in the ballistic performance, but with no plateau regions and the straight lines in their logarithmic relation between chamber pressure and burning rate may be due to the relatively low dependence of the burning rates on the pressure values [20].

The results obtained indicate that the suggested modifiers showed improvements in the ballistic performance of these propellants at $-20{ }^{\circ} \mathrm{C}$ and $+50^{\circ} \mathrm{C}$, as indicated by exhibiting either a plateau or a linear relationship between the burning rate and the chamber pressure. It is worth mentioning here that the plateau logarithmic relationship obtained between the burning rate and the chamber pressure is preferred over the linear logarithmic one, but both lead to better ballistics, combustion stability and lower pressure levels in the combustion chamber of these samples [20].

Finally, the results of the ballistic performance parameters obtained from the thermo-chemical calculations which are presented in this study, combustion temperature (T) and specific impulse (SP) are listed in Table 3. The values of the specific impulse obtained from formulations S1-S6 are nearly the same as that obtained for the control sample. These values indicate that the replacement of such propellant types by others does not affect the proposed rocket mission.

\section{Conclusions}

The suggested burning rate modifiers containing different copper salts decreased the ignition temperature of the propellants and increased their heat of combustion with respect to the control sample. Samples containing copper acetate had 
the lowest ignition temperature and the highest heat of combustion of all the samples studied. Increasing the percentage of copper salicylate in the sample caused an increase in the heat of combustion. The addition of all of the burning rate modifiers studied enhanced the mechanical properties (maximum stress and strain at maximum stress) of the control propellant sample. Also they led to enhancement in the ballistic performance characteristics of the prepared propellant compositions, as revealed by exhibiting a plateau or linear relationship between the burning rate and the chamber pressure during their combustion. The burning rate modifiers did not significant effect the specific impulse and combustion temperature of the propellant.

\section{References}

[1] Venkatachalam S., Santhosh G., Ninan K.N., High Energy Oxidisers for Advanced Solid Propellants and Explosives, Advances in Solid Propellant Technology, $1^{\text {st }}$ Int. HEMS1 Workshop, Ranchi, India, 2002, 87.

[2] Folly P., Mäder P., Propellant Chemistry, CHIMIA Int. J. Chem., 2004, 58, 374.

[3] Fry R.S., Solid Propellant Test Motor Scaling, The Johns Hopkins University, Chemical Propulsion Information Agency, Columbia, Maryland, 2001.

[4] Nadir Y., Burl D., Walter G., William E., Solid Propellant Burning Rate from Strand Burner Pressure Measurement, Propellants Explos. Pyrotech., 2008, 33,109.

[5] Yasuyoshi M., Kazuo H., Effect of Initial Temperature and Pressure on the Burning Rate of AGAT/AN Mixtures, J. Energ. Mater., 2011, 29, 26.

[6] Joshi A.D., Singh H., Effect of Certain Lead and Copper Compounds as Ballistic Modifier for Double Base Rocket Propellants, J. Energ. Mater., 1992, 10, 299.

[7] Singh H., Rao K.R.K., Raman K.V., Ballistic Modification of Composite Modified Double-Base Propellants Containing Ammonium Perchlorate, Propellants Explos. Pyrotech., 1987, 13, 13.

[8] Singh H., Rao K.R.K., Thermal Decomposition Studies of Catalysed Double Base Propellants, Proc. Indian Acad. Sci. (Chem. Sci.), 1984, 93(2), 93.

[9] Stiles S., McCool P., Ballistic Modifier Formulation for Double Base Propellant, US Patent 8,864,923 B1, 2014.

[10] Demidova L.A., Denisyuk A.P., Effect of Some Catalysts on Combustion of Doublebase Propellants, Comb. Expl. Shock Waves (Engl. Transl.), 2004, 311.

[11] Chen P., Zhao F.Q., Luo Y., Hu R.Z., Gao S.L., Zheng Y.M., Deng M.Z., Gao Y., Thermal Decomposition Behavior and Non-isothermal Decomposition Reaction of Copper(II) Salt of 4-Hydroxy-3,5-dinitropyridine Oxide and Its Application in Solid Rocket Propellant, Chinese J. Chem., 2004, 22, 1056.

[12] Yi J.H., Zhao F.Q., Wang B.Z., Liu Q., Zhou C., Hu R.Z., Ren Y.H., Xu S.Y., Xu K.Z, Ren X.N., Thermal Behaviors, Nonisothermal Decomposition Reaction Kinetics, 
Thermal Safety and Burning Rates of BTATz-CMDB Propellant, J. Hazard. Mater, 2010, 181, 432 .

[13] Singh H., Rao K.R.K., Mechanism of Combustion of Catalyzed Double Base Propellants, Combust. Flame, 1988, 71, 205.

[14] Muller D., Stewart J., Twin Screw Extrusion for the Production of Stick Propellants, J. Hazard. Mater., 1984, 9, 47.

[15] Suceska M., Test Methods for Explosives, Springer, Heideleberg, 1995; ISBN 9780387945552.

[16] Herder G., Weterings F.P., Klerk W.P.C.D., Mechanical Analysis on Rocket Propellants, J. Therm. Anal. Calorim., 2003, 72, 921.

[17] Frosch R.A., Ramohalli N.R.K., Silicone Containing Solid Propellant, US Patent 4210474, 1998.

[18] Bathelt H., Volk F., The ICT-Thermochemical Data Base, 27th Int. Annu. Conf. ICT, Karlsruhe, Germany, 1996, 91.

[19] Volk F., Bohn M.A., Wunsch G., Determination of Chemical and Mechanical Properties of Double Base Propellants during Aging, Propellants Explos. Pyrotech., 1987, 13, 81 .

[20] De Luca L., Price E.W., Summerfield M., Nonsteady Burning and Combustion Stability of Solid Propellants, in: Progress in Astronautic and Aeronautics, vol. 143, AIAA, Washington, DC, 1992, ISBN 978-1-56347-014-1.

[21] French J.C., Non-Linear Combustion Stability Prediction of SRMs Using SPP/ SSP, 39 $9^{\text {th }}$ AIAA Joint Propulsion Conference, Huntsville, AL, 20-23 July 2003.

[22] Fry R.S., Solid Propellant Subscale Burning Rate Analysis Methods for U.S. and Selected NATO Facilities, The Johns Hopkins University, Chemical Propulsion Information Agency, Columbia, Maryland, 2002.

[23] Lengellé G., Duterque J., Trubert J.F., Combustion of Solid Propellants, the RTO/ VKI Special Course on Internal Aerodynamics in Solid Rocket Propulsion, held in Rhode-Saint-Genèse, Belgium, 27-31 May 2002, and published in RTO-EN-023, 2004, ISBN 92-837-1103-3. 
